\title{
PLANEJAMENTO ORÇAMENTÁRIO PÚBLICO POR MEIO DO CRÉDITO SUPLEMENTAR
}

BRAGA, Andiara de Jesus ${ }^{1}$ CIRIBELI, João Paulo ${ }^{2}$

MASSARDI, Wellington de Oliveira ${ }^{3}$

MENDES, Wanderson de Almeida ${ }^{4}$

\author{
Recebido em: 2020.11 .04
}

Aprovado em: 2021.01.13

ISSUE DOI: $10.3738 / 1982.2278 .3860$

RESUMO: O presente estudo tem por objetivo geral criar um índice que mensure a eficiência dos municípios face ao planejamento orçamentário das receitas e despesas anuais, e correlacioná-la com o uso dos créditos suplementares, de forma a basilar escores que meçam o grau de assertividade e consequente grau de planejamento dos municípios. Em relação à classificação metodológica, trata-se de pesquisa aplicada, descritiva, quantitativa e bibliográfica. Sobre o tratamento dos dados, utilizou-se de dados secundários obtidos do FINBRA e do TCE-M, com emprego de fórmulas, índices e a estatística descritiva. Com base nos resultados, constatou-se que 12,25\% do total de 457 municípios analisados possuem um alto nível de precisão orçamentária; os municípios que apresentaram um nível baixo de precisão orçamentária, representam $10,72 \%$ do total; e $77,02 \%$ do total de municípios se encontram em um nível regular de precisão orçamentária. Pode-se concluir que, o planejamento orçamentário municipal feito de forma correta, juntamente com um conhecimento melhor por parte da gestão pode reduzir os níveis de suplementação orçamentária dos municípios.

Palavras-chave: Orçamento Público. Créditos Suplementares. Minas Gerais.

\section{PUBLIC BUDGET PLANNING THROUGH SUPPLEMENTARY CREDIT}

SUMMARY: The purpose of the present study is to create an index that measures the efficiency of municipalities in relation to the budget planning of annual revenues and expenses and correlates with the use of supplementary credits in order to base scores that measure the degree of assertiveness and consequent degree planning of municipalities. In relation to the methodological methodology, it is applied, descriptive, quantitative and bibliographic research. Data were collected using secondary data from FINBRA and TCE-M, e-mail formulas, indexes and descriptive statistics. Based on the results, it was found that $12.25 \%$ of the total of 457 municipalities analyzed, a high level of budgetary accuracy; the municipalities that presented a low cost of budgetary precision represent $10.72 \%$ of the total; and $77.02 \%$ of the total municipalities are at the normal level of budgetary accuracy. It can be concluded that municipal budget planning done in the right way, together with a better knowledge by the administration can reduce the levels of budgetary supplementation of the municipalities.

Keywords: Public Budget. Supplementary Credits. Minas Gerais.

\footnotetext{
${ }^{1}$ Graduada em Administração. Faculdade Governador Ozanam Coelho - FAGOC

${ }^{2}$ Dr. em Administração; Mestre em Gestão de Empresas; Especialista em Gestão da Informação no Agronegócio; Graduação em Administração com Habilitação em Adm. de Cooperativas pela UFV. Professor da UNIFAGOC e Gestor Municipal de Convênios - GMC da Prefeitura Municipal de Guiricema.

${ }^{3}$ Mestre em Administração. Graduado em Ciências Contábeis.

${ }^{4}$ Doutorando e Mestre em Administração pela UFV; Especialista em Engenharia e Gerenciamento de Manutenção e MBA Executivo em Gestão de Produção e Qualidade pela UCAM; Graduado em Administração pela FAGOC.
} 


\section{INTRODUÇÃO}

Ao se iniciar o ano de 2016, instaurou-se um processo de impeachment contra a presidente brasileira Dilma Rousseff, por crime de responsabilidade. De acordo com a Lei 1.079/50, em seu Artigo 10, é crime "exceder ou transportar, sem autorização legal, as verbas do orçamento" (BRASIL, 1950). Portanto, os atrasos nos repasses aos bancos públicos, com o objetivo de maquiar as contas públicas, e a abertura irregular de créditos suplementares sem a autorização do legislativo caracterizaram os motivos que levaram ao processo de afastamento da presidente de seu cargo.

Dezesseis anos depois de ser sancionada a Lei Complementar $n^{\circ} 101$, de 4 de maio de 2000 - Lei de Responsabilidade Fiscal - LRF, que estabelece que toda ação realizada pelo gestor público deve ser planejada e transparente, prevenindo riscos e corrigindo desvios capazes de afetar o equilíbrio das contas públicas (BRASIL, 2000), muitos gestores ainda tomam decisões que infringem a lei, causando mal a toda nação.

Com o intuito de diminuir os gastos públicos, o governo federal criou a Proposta de Emenda Constitucional - PEC 241, que tem como objetivo limitar os gastos públicos durante vinte anos. Dessa forma, o governo federal acreditou ser possível melhorar a situação financeira do país com essa medida, além de buscar superar a crise econômica enfrentada naquele período (ALESSI, 2016).

O orçamento é baseado em princípios que são indispensáveis para uma execução fiel de um programa de governo (KOHAMA, 2012). A Grécia, no momento em que publicava dados irreais sobre a contabilidade do país, na tentativa de encobrir a verdadeira situação vivida, violou o princípio da publicidade orçamentária, o qual, segundo Bezerra Filho (2006) determina que o orçamento seja divulgado com veracidade pelos veículos oficiais de publicação.

O governo de Minas Gerais também apresenta alguns problemas orçamentários, segundo o Dardanhan (2016). Os números do estado mostraram que foram ultrapassados 46,55\% do limite prudencial com gastos de pessoal, enquanto o limite máximo estabelecido pela Lei Complementar $n^{\circ} 101$, de 4 de maio de 2000 - Lei de Responsabilidade Fiscal-LRF é de 49\% para esse tipo de despesa (BRASIL, 2000).

Nesse contexto, verifica-se que um orçamento mais perto da realidade é importante para a saúde financeira e para um bom desenvolvimento das entidades públicas ou privadas; é essencial, para uma gestão eficiente e eficaz, pois é através dele que se medirá a boa ou má qualidade de uma administração, refletindo diretamente no bem-estar da sociedade (XEREZ, 2013). 
Entretanto, quando há uma má elaboração orçamentária ou imprevistos no planejamento, como por exemplo variações de preços no mercado e repriorização das ações governamentais, é necessário que o gestor faça uso de créditos suplementares, que o Artigo 41 da Lei 4.320/64 define como aqueles usados para o reforço de uma dotação orçamentária e para corrigir os erros não planejados no orçamento (BRASIL, 1964). Nesse sentido, considera-se que não houve planejamento por parte da gestão, tornando-a ineficiente.

No meio acadêmico, são vários os estudos que abordam o crédito suplementar como um elemento que, quando usado em demasia, caracteriza um mau planejamento orçamentário. Dentre esses trabalhos, destaca-se o de Albuquerque (2014), segundo o qual o uso inadequado das receitas provoca uma excessiva e abusiva abertura de créditos adicionais suplementares para reforçar dotações insuficientes.

Além desse, pode-se citar o estudo de Costa (2010), que buscou analisar a relevância do orçamento como instrumento da gestão pública, mostrando a grande importância de um planejamento orçamentário.

Considerando que o planejamento orçamentário venha a ser ineficiente quando se pratica o uso constante dos créditos suplementares, procura-se saber: qual o nível de eficiência e previsão dos municípios mineiros na elaboração do orçamento público no que se refere ao uso de créditos suplementares?

O presente estudo tem como objetivo mensurar a eficiência dos municípios diante o planejamento orçamentário, considerando a relação do valor orçado com o valor realizado.

Para a elaboração deste estudo e especificação das temáticas tratadas, o presente trabalho está estruturado em cinco seções, onde além desta introdução, o próximo tópico consiste na revisão de literatura, onde se discute sobre o orçamento público brasileiro, os créditos adicionais e o planejamento orçamentário. Na seção três será abordada a metodologia utilizada no estudo. A seção quatro irá trazer os resultados e discussões da realização do trabalho. Na última seção é feita as considerações finais do presente estudo.

\section{REVISÃO DE LITERATURA}

\subsection{Orçamento Público Brasileiro}

O orçamento é um instrumento utilizado pelas esferas governamentais para organizar seus recursos financeiros (HADDAD; MOTA, 2010). Sua principal função é fixar despesas e estimar 
receitas, demonstrando onde serão aplicados os recursos e quem serão os responsáveis pela aplicação deles (RONCALLI, 2009; ANDRADE, 2013).

Essa forma de planejamento surgiu no século XI na Inglaterra, com o intuito de evitar a criação de tributos pelos soberanos no país. No Brasil, o primeiro orçamento foi previsto na Constituição de 1824, porém só foi votado para o exercício de 1831-1832 (CERVO, 2012).

Desde aquela época, as leis que instituem o sistema de planejamento e definem os objetivos e os meios pelos quais se pode alcançar o planejamento efetivo são o Plano Plurianual PPA, a Lei de Diretrizes Orçamentárias - LDO e a Lei Orçamentária Anual - LOA, descritos no Quadro 1.

A fim de alcançar seus objetivos, organizando-se e fazendo uso dos meios legais para atingirem a efetividade em suas ações, as administrações públicas nos níveis federal, estadual e municipal usam instrumentos como o PPA, a LDO e a LOA para obterem os melhores resultados em termos de investimento e prestação de serviços, priorizando a necessidade da coletividade (MORO, 2011; BEZERRA FILHO, 2006; KOHAMA， 2012; SANTOS, 2001; ALBUQUERQUE, 2014).

No que diz respeito a essas leis, segundo a Constituição Federal, a LDO compreende as despesas de capital, orienta a elaboração da LOA, dispõe sobre as alterações na legislação tributária e estabelece a política de aplicação das agências financeiras. A LOA compreende o orçamento fiscal referente aos poderes da União, o orçamento de investimento das empresas em que a União detenha maioria do capital investido e o orçamento da seguridade social abrangendo todas as entidades e órgãos a ela vinculados (BRASIL, 1988).

Quadro1 - Definição e aplicação das leis que regem o orçamento público

\begin{tabular}{|c|l|}
\hline LEIS & \multicolumn{1}{c|}{ DEFINIÇÃO } \\
\hline $\begin{array}{c}\text { Plano Plurianual } \\
\text { PPA }\end{array}$ & $\begin{array}{l}\text { É um plano de longo/médio prazo que vigora por um período de 4 anos, no qual procura-se } \\
\text { ordenar as ações do governo nas três esferas (municipal, estadual e federal), de forma a } \\
\text { orientar genericamente as despesas de capital e outras delas decorrentes, assim como os } \\
\text { programas de duração continuada. Sua vigência vai do segundo ano do mandato atual até o } \\
\text { final do primeiro ano do mandato subsequente. }\end{array}$ \\
\hline $\begin{array}{c}\text { Lei de Diretrizes } \\
\text { Orçamentárias } \\
\text { LDO }\end{array}$ & $\begin{array}{l}\text { É um plano de curto prazo que norteia a elaboração dos orçamentos anuais, sendo, portanto, } \\
\text { elaborada anualmente, de forma a adequá-los às diretrizes, objetivos e metas estabelecidos } \\
\text { pelo Plano Plurianual. A LDO também tem a função de orientar a elaboração da LOA. }\end{array}$ \\
\hline $\begin{array}{c}\text { Lei Orçamentária } \\
\text { Anual - LOA }\end{array}$ & $\begin{array}{l}\text { É um plano de curto prazo realizado anualmente, que viabiliza a concretização das situações } \\
\text { planejadas no Plano Plurianual, de forma a respeitar a LDO e alcançar os objetivos } \\
\text { determinados no PPA. }\end{array}$ \\
\hline
\end{tabular}

Fonte: Bezerra Filho (2006, p. 21-24) e Kohama (2003, p. 57-61). 
Moro (2011) alega que os gestores devem usar os recursos de forma a pensar na coletividade, pois, além de serem escassos, todos os recursos são públicos. Portanto, a sua utilização de maneira correta e legal é uma ação que todos os gestores devem priorizar.

\subsection{Os diferentes tipos de créditos adicionais: uma visão panorâmica}

Os créditos adicionais são uma maneira usada pelas administrações públicas para autorizar despesas que não foram computadas no orçamento anual ou que foram escassas. Podem ser compreendidos como uma alteração no orçamento, com a finalidade de corrigir e acertar as deficiências ocorridas no orçamento anual (MORO, 2011; RONCALLI, 2009; HADDAD; MOTA, 2010).

Eles ocorrem devido à diferença entre a receita prevista e a arrecadada na construção do orçamento público municipal, além da desarmonia entre a despesa fixada e a realizada, quando surgir a necessidade de gastos que não foram previstos ou foram insuficientes mediante a previsão na LOA (KOHAMA, 2003; BEZERRA FILHO, 2006; ALBUQUERQUE, 2014).

De acordo com Angélico (2009, p. 29), “os créditos adicionais, segundo suas finalidades, classificam-se em créditos suplementares, créditos especiais e créditos extraordinários", e cada modalidade dos créditos adicionais (Quadro 2) é considerada uma forma de alteração do orçamento público, sendo, portanto, proporcional a ele.

Quadro 2: Modalidades de créditos adicionais

\begin{tabular}{|c|c|c|c|}
\hline MODALIDADES & $\begin{array}{c}\text { CRÉDITOS } \\
\text { SUPLEMENTARES }\end{array}$ & $\begin{array}{l}\text { CRÉDITOS } \\
\text { ESPECIAIS }\end{array}$ & CRÉDITOS EXTRAORDINÁRIOS \\
\hline OBJETIVO & $\begin{array}{l}\text { Reforçar dotação } \\
\text { orçamentária existente. }\end{array}$ & $\begin{array}{l}\text { Atender a programas, } \\
\text { projetos, atividades, } \\
\text { operações especiais não } \\
\text { contempladas no } \\
\text { orçamento. }\end{array}$ & $\begin{array}{l}\text { Atender a despesas imprevisíveis e } \\
\text { urgentes, em decorrência de guerra, } \\
\text { comoção interna ou calamidade } \\
\text { pública. }\end{array}$ \\
\hline $\begin{array}{l}\text { AUTORIZAÇÃO } \\
\text { LEGISLATIVA }\end{array}$ & $\begin{array}{l}\text { Prévia, podendo ser } \\
\text { incluída na própria Lei de } \\
\text { Orçamento ou em Lei } \\
\text { Especial. }\end{array}$ & Prévia em Lei Especial. & Independem de Lei autorizativa. \\
\hline $\begin{array}{l}\text { FORMADE } \\
\text { ABERTURA }\end{array}$ & $\begin{array}{l}\text { Através de Decreto do } \\
\text { Poder Executivo. }\end{array}$ & $\begin{array}{l}\text { Através de Decreto do } \\
\text { Poder Executivo. }\end{array}$ & $\begin{array}{l}\text { Através de Decreto do Poder } \\
\text { Executivo, após decretado o estado de } \\
\text { calamidade pública ou outro de } \\
\text { natureza idêntica, que deles dará } \\
\text { imediato conhecimento ao Poder } \\
\text { Legislativo. }\end{array}$ \\
\hline
\end{tabular}


Quadro 2: Modalidades de créditos adicionais

\begin{tabular}{|c|c|c|c|}
\hline MODALIDADES & $\begin{array}{c}\text { CRÉDITOS } \\
\text { SUPLEMENTARES }\end{array}$ & $\begin{array}{l}\text { CRÉDITOS } \\
\text { ESPECIAIS }\end{array}$ & CRÉDITOS EXTRAORDINÁRIOS \\
\hline $\begin{array}{l}\text { ORIGEM DOS } \\
\text { RECURSOS }\end{array}$ & $\begin{array}{l}\text { Superávit Financeiro; } \\
\text { Excesso de arrecadação; } \\
\text { Anulação total ou parcial } \\
\text { de dotação orçamentária. }\end{array}$ & $\begin{array}{l}\text { Superávit Financeiro; } \\
\text { Excesso de arrecadação; } \\
\text { Anulação total ou parcial } \\
\text { de dotação orçamentária. }\end{array}$ & $\begin{array}{l}\text { Não é necessária a indicação de } \\
\text { recursos para a abertura de créditos } \\
\text { extraordinários. }\end{array}$ \\
\hline VIGÊNCIA & $\begin{array}{l}\text { Desde a sua abertura, até } \\
\text { o fim do ano a que se } \\
\text { refere o orçamento em } \\
\text { execução. }\end{array}$ & $\begin{array}{l}\text { Desde a sua abertura, até } \\
\text { o término do exercício em } \\
\text { que forem abertos, salvo } \\
\text { se o ato de autorização for } \\
\text { promulgado nos últimos } \\
\text { quatro meses do } \\
\text { exercício, quando poderão } \\
\text { vigorar até o término do } \\
\text { exercício subsequente. }\end{array}$ & $\begin{array}{l}\text { Desde a sua abertura até o término do } \\
\text { exercício em que forem abertos, salvo } \\
\text { se o ato de autorização for promulgado } \\
\text { nos últimos quatro meses do exercício, } \\
\text { quando poderão vigorar até o término } \\
\text { do exercício subsequente. Só atendem } \\
\text { aos prazos supracitados enquanto } \\
\text { permanecer a situação emergencial que } \\
\text { justificou sua abertura. }\end{array}$ \\
\hline LIMITE & $\begin{array}{l}\text { Obrigatório, indicado na } \\
\text { lei de autorização e no } \\
\text { decreto de abertura. }\end{array}$ & $\begin{array}{l}\text { Obrigatório, indicado na } \\
\text { lei de autorização e no } \\
\text { decreto de abertura. }\end{array}$ & $\begin{array}{l}\text { Obrigatório, indicado no decreto de } \\
\text { abertura. }\end{array}$ \\
\hline PRORROGAÇÃO & Jamais permitida. & $\begin{array}{l}\text { Só para o exercício } \\
\text { seguinte, se autorizado em } \\
\text { um dos } 4 \text { últimos meses, e } \\
\text { desde que a lei } \\
\text { autorizativa assim o } \\
\text { permita. }\end{array}$ & $\begin{array}{l}\text { Só para o exercício seguinte, se } \\
\text { autorizado em um dos 4últimos meses, } \\
\text { e desde que ao decreto de abertura } \\
\text { assim o permita. }\end{array}$ \\
\hline
\end{tabular}

Fonte: Machado Jr. e Reis (2002, p. 120), Bezerra Filho (2006, p. 34-39) e Brasil (1988).

Existem inúmeros fatores que podem influenciar na abertura dos créditos adicionais pelo poder público. Variações do preço de mercado, incorreções no planejamento, omissões orçamentárias e repriorização das ações governamentais são alguns dos motivos que podem acarretar o uso dos créditos adicionais (MACHADO JR. e REIS, 2002; ROCHA, 2001).

\subsection{Créditos suplementares e planejamento orçamentário}

Os créditos suplementares podem ser definidos como uma maneira de reforçar ou complementar alguma dotação que foi insuficiente segundo a previsão orçamentária (BRASIL, 1964; KOHAMA, 2012; ANGÉLICO, 2009; RONCALLI, 2009; BEZERRA FILHO, 2006).

De acordo com o Artigo 43 da Lei 4.320/64, os recursos disponíveis para a abertura dos créditos suplementares podem ser:

I - o superávit financeiro apurado em balanço patrimonial do exercício anterior;

II - os provenientes de excesso de arrecadação

III - os resultantes de anulação parcial ou total de dotações orçamentárias ou de créditos adicionais, autorizados em Lei;

IV - o produto de operações de credito autorizadas, em forma que juridicamente possibilite ao poder executivo realizá-las. (BRASIL, 1964, p. 1140).

A anulação parcial ou total de dotações é a fonte de recursos mais utilizada na abertura de créditos suplementares e especiais, pois podem-se realocar os saldos para as dotações mais 
necessárias, desde que entre programas diferentes da mesma unidade ou atividades e projetos de um mesmo programa (ALBUQUERQUE, 2014; BEZERRA FILHO, 2006).

O poder executivo deve enviar seu planejamento orçamentário anual (LOA) ao poder legislativo para que este autorize as despesas, bem como o percentual de créditos suplementares solicitados, de acordo com o orçamento de cada município, o qual pode ser ou não aprovado pelo legislativo (MORO, 2011).

Com intenção de diminuir os pedidos de suplementação, a legislação permite que a própria LOA dê poderes ao executivo para suplementar, dentro de um limite percentual estabelecido (ANGÉLICO, 2009; KOHAMA 2012).

Em Minas Gerais, o limite percentual pode chegar a 30\% do total do orçamento, dependendo do município. Nos casos em que esse limite é ultrapassado, o Tribunal de Contas do Estado de Minas Gerais-TCEMG "alerta" o município infrator, solicitando a redução de suplementações, uma vez que o aumento desse percentual implica o mau planejamento orçamentário (BRASIL 1964).

Nesse contexto, Angélico (2009) afirma que os créditos orçamentários ocorrem com frequência, pois as dotações se esgotam antes do término do exercício. Essa deficiência deve-se à falta de previsão adequada e, consequentemente, à ausência de planejamento.

O planejamento orçamentário procura fazer um diagnóstico da situação atual, com a finalidade de promover ações ou modificações, visando atingir o melhor emprego dos meios disponíveis para minimizar os problemas econômicos e sociais existentes (KOHAMA, 2012; RONCALLI, 2009; ANDRADE, 2013).

Supondo que a administração se baseie concretamente no processo de planejamento, cujas técnicas utilizadas visem à consolidação de seus objetivos e metas, a existência dos créditos suplementares tende a reduzir-se ou talvez seja de uso atípico (KOHAMA, 2012; ANGÉLICO, 2009); por outro lado, a falta de planejamento, uma definição mais clara dos objetivos e metas e um sistema de avaliação e controle de resultados são alguns dos fatores que influenciam negativamente na redução da utilização dos créditos suplementares (KOHAMA, 2003, p. 210)

Os orçamentos das prefeituras modestas possuem, por força da lei, as características extrínsecas de orçamento-programa. Mas seu conteúdo é fictício, nada está programado. A execução orçamentária desenvolve-se ao sabor das necessidades emergentes. Os orçamentos aparentam planejamento por força dos modelos oficiais padronizados os quais as prefeituras são obrigadas a preencher. (ANGÉLICO, 2009, p. 32). 
Problemas que vierem a ocorrer no orçamento podem comprometer o sucesso da administração e, consequentemente, aumentar os riscos de punição pelos órgãos fiscais (ANDRADE, 2013).

O orçamento é um planejamento da administração pública, e o gestor municipal, fazendo o uso constante dos créditos suplementares, acaba tornando-o ineficiente. Portanto, os créditos suplementares são vistos como elementos perturbadores, pois têm a finalidade de cobrir falhas de planejamento durante a execução orçamentária (ALBUQUERQUE, 2014; ROCHA, MARCELINO; SANTANA, 2013).

\section{METODOLOGIA}

Com o intuito de atingir o objetivo deste estudo - criar um índice que mensure a eficiência dos municípios no planejamento por meio da mensuração anual e correlacioná-lo com o uso excessivo de créditos suplementares -, realizou-se uma pesquisa descritiva, a qual se conceitua como aquela que visa retratar as características de determinada população ou fenômeno, ou o estabelecimento de relação entre variáveis sem a interferência do autor (KAUARK; MANHÃES; MEDEIROS, 2010).

Em relação à forma de abordagem dos dados, a pesquisa foi predominantemente de caráter quantitativo, na qual os resultados podem ser quantificados, concentrando-se na objetividade. Quanto aos procedimentos utilizados, a pesquisa é bibliográfica, uma vez que se utilizou de documentos elaborados por outros autores sobre o tema abordado.

Quanto à natureza do estudo, pode-se dizer que foi aplicada, a qual, que segundo Gerhardt e Silveira (2009, p. 35), “objetiva gerar conhecimentos para aplicação prática, dirigidos à solução de problemas específicos envolvendo verdades e interesses locais".

A coleta dos dados necessários para contemplar a pesquisa foi realizada através dos dados secundários do banco de dados sobre Finanças do Brasil - FINBRA, disponível no site do Tesouro Nacional, e de dados do site do Tribunal de Contas do Estado de Minas Gerais - TCEMG. O período utilizado na análise foi o ano de 2012.

A amostra do estudo constitui-se de 457 municípios do estado de Minas Gerais com menos de 10.188 habitantes. A escolha deveu-se ao coeficiente mínimo $(0,6)$ do Fundo de Participação dos Municípios - FPM, que é uma importante fonte de receitas das prefeituras e à expectativa de que os municípios de pequeno porte têm mais dificuldade em elaborar seus orçamentos precisamente, portanto considera-se que são municípios com maior dificuldade de 
planejamento (KOHAMA, 2012), tendo consequentemente um índice baixo de previsão sobre o planejamento.

A eficiência orçamentária foi analisada em 3 variáveis distintas (ver Quadro 3), que buscam mensurar a previsão de receitas, fixação de despesas e o uso de créditos suplementares. Para isso, foram calculados indicadores, que foram utilizados para o cálculo do Índice de Precisão Orçamentária dos Municípios - IPOM.

Quadro 3: Variáveis utilizadas na verificação da eficiência orçamentária

\begin{tabular}{|c|c|c|}
\hline VARIÁVEL $(\mathbf{X i )}$ & FÓRMULA & FONTE \\
\hline Receita & $\left\lceil\left[1-\left(\frac{\text { receita executada }}{\text { receita prevista }}\right) \times 100\right]\right.$ & FINBRA \\
\hline Despesa & $\mid\left[1-\left(\frac{\text { despesa executada }}{\text { despesa prevista }}\right) \times 100\right]$ & FINBRA \\
\hline Créditos Suplementares & $\frac{\text { crédito suplementar }}{\text { total do orçamento }}$ & TCEMG \\
\hline IPOM & $\frac{\text { IReceita + IDespesa + (ICrédito Suplementar x 2) }}{4}$ & \\
\hline
\end{tabular}

Fonte: dados da pesquisa.

Verifica-se, no Quadro 3, que as fórmulas estão em módulo. Optou-se por modularas variáveis receita $(\mathrm{Xi})$ e despesa $(\mathrm{Xi})$, por se entender que os valores resultantes de sua aplicação podem apresentar importâncias negativas quando a receita ou a despesa executada for superior à receita ou à despesa prevista no orçamento, respectivamente.

Os indicadores estimados pelas fórmulas serão considerados piores quando se afastarem no número 1 (para mais ou para menos). Este percentual representará a margem de erro do previsto frente ao realizado, ou seja, aquilo que foi estimado na Lei Orçamentária Anual e o efetivamente executado no ano seguinte ao votado pela Câmara Municipal.

Portanto, ao se avaliar a relação existente, caso o resultado seja subestimado (previsto menor do que o executado), teremos um valor positivo maior do que 1; por outro lado, se a relação for superestimada (previsto maior do que o executado), teremos um resultado também positivo, por ser modular, mas menor do que 1. A terceira possibilidade é o executado ser igual ao previsto - nesse caso, teremos variável Xi igual a 1 com máxima eficiência na previsibilidade orçamentária.

Por meio do Quadro 3 também pode ser visualizada a fórmula utilizada para verificar os índices de créditos suplementares que medem a quantidade de suplementação realizada pelo município no ano avaliado, além do IPOM, que foi criado pelos autores para verificar o nível de 
precisão orçamentária dos municípios analisados. Esse índice foi obtido através da média ponderada entre os coeficientes de receita, despesa e crédito suplementar, sendo que, para o crédito suplementa, foi dado o peso 2 , de forma arbitrária pelos autores, porque considera-se que esse coeficiente tem grande importância no que se refere ao planejamento orçamentário.

O Índice de Precisão Orçamentária dos Municípios - IPOM é utilizado para identificar o grau de precisão dos municípios em relação à previsão orçamentária, quanto mais perto do 0 , melhor o grau de precisão orçamentária.

\section{RESULTADO E DISCUSSÃO}

Para analisar a eficiência orçamentária dos municípios estudados, tabularam-se os dados obtidos junto ao TCE-MG e ao FINBRA, e posteriormente foram aplicadas as fórmulas do Quadro 3, com o intuito de acurar os índices de eficiência orçamentária, e assim balizar o grau de planejamento orçamentário dos municípios.

As estatísticas descritivas evidenciadas na Tabela 1 apontam que a média da variável receita apresentou uma diferença, em relação à mediana da variável "despesa", de 0,31. Essa diferença é pequena, demonstrando que, em relação a mediana, os índices de previsão e execução dos municípios, no que diz respeito à receita e à despesa, são bem próximos.

Tabela 1: Estatísticas descritivas das variáveis analisadas

\begin{tabular}{ccccccc}
\hline Variável & Mínimo & Máximo & Mediana & Desvio-padrão & Assimetria & Curtose \\
\hline Receita & 0,00 & 72,51 & 13,00 & 10,53 & 1,24 & 2,92 \\
\hline Despesa & 0,05 & 86,69 & 12,69 & 11,04 & 1,47 & 4,68 \\
\hline $\begin{array}{c}\text { Crédito } \\
\text { Suplementar }\end{array}$ & 0,00 & 134,50 & 34,48 & 16,97 & 97,01 & 276,51 \\
\hline
\end{tabular}

Fonte: dados da pesquisa.

O desvio padrão da receita foi de 10,53 e o da despesa, 11,04. Tal fato evidencia um maior número de municípios próximos à média da receita, que em geral tendem a seguir projeções do ano anterior ou dos anos anteriores. Quanto à despesa, apesar de sua previsão também seguir padrões cunhados em anos anteriores, sua execução pode fugir ao previsto, em geral por conta da celebração de convênios (transferências voluntárias) ou situações de emergência e calamidade pública.

Dos 457 municípios analisados, apenas Alpercata (localizado na região do Vale do Rio Doce) e Tiradentes (localizado na região do Campo das Vertentes) obtiveram índices mínimos das variáveis "receita" e "despesa", respectivamente - o que demonstra alguma capacidade de planejamento orçamentário.

Nucleus, v.18, n.1, abr. 2021 
As estatísticas descritivas da variável "crédito suplementar" podem ser visualizadas na Tabela 1. Nesse contexto, Angélico (2009) e Kohama (2012) afirmam que existe um limite percentual estabelecido para os pedidos de suplementação no orçamento. Para os municípios de Minas Gerais, esse percentual pode chegar a 30\% do orçamento, segundo o TCEMG (BRASIL, 1964). Contudo, conforme os dados discriminados na Tabela 1, a mediana dos municípios mineiros em relação aos níveis de suplementação é de 34,48; isso mostra que a grande maioria dos municípios ultrapassa o limite preestabelecido. De acordo com Angélico (2009), essa deficiência deve-se à falta de previsão adequada e, consequentemente, à ausência de planejamento.

Por outro lado, os resultados da Tabela 1 demonstram também que existem municípios com valores bem inferiores à média, não suplementando seu orçamento no ano de 2012, como o caso das cidades de Divinésia, Crucilândia, Bandeira, Araporã e Inimutaba, que obtiveram o índice mínimo de 0,00 para a variável "crédito suplementar". Já o índice máximo da variável é representado pelo município de Virgínia, que será visto na descrição da Tabela 2.

Após estimar a receita, a despesa e o crédito suplementar, foi possível obter o Índice de Precisão Orçamentária dos Municípios - IPOM. Esse índice é utilizado para identificar o grau de precisão dos municípios em relação à previsão orçamentária. Quanto mais perto do 0 , melhor o grau de precisão orçamentária.

Tabela 2: Margem de erro orçamentário dos municípios mineiros

\begin{tabular}{ccccccc} 
Índice & Mínimo & Máximo & Média & Desvio-padrão & Assimetria & Curtose \\
\hline IPOM & 1,35 & 98,40 & 25,50 & 9,80 & 1,89 & 8,61 \\
\hline Fonte: dados da pesquisa. & & & & & &
\end{tabular}

As estatísticas descritivas identificadas na Tabela 2 demonstram que, em média, os municípios têm uma precisão em relação ao planejamento orçamentário de 25,50. Porém, essa média é influenciada pelo município de Virgínia - região sudoeste de Minas Gerais -que chegou a atingir o índice máximo da variável $(98,40)$.

Esse município recebeu convênios não planejados (transferências voluntárias) para o ano de 2012, e teve sua receita e despesa executadas muito maiores que o previsto, aumentando consideravelmente a porcentagem de suplementação em seu orçamento. No que tange às transferências voluntárias, estas estão baseadas na Lei 101 de 04 de maio de 200 - LRF, segundo a qual "entende-se por transferência voluntária a entrega de recursos correntes ou de capital a outro ente da Federação, a título de cooperação, auxílio ou assistência financeira, que não decorra 
de determinação constitucional, legal ou os destinados ao Sistema Único de Saúde” (BRASIL, 2000).

O município de Crucilândia, localizado a 115 km de Belo Horizonte, na região Sudeste de Minas Gerais, com apenas 4.800 habitantes, foi o que apresentou o maior grau de precisão orçamentária, da ordem de 1,35 (Tabela 2). Acredita-se que o resultado dessa precisão se deve a um possível planejamento municipal, assim como à não incidência de eventos atípicos. Fundamentando os fatos Kohama (2012) e Angêlico (20096) argumentam que uma administração que faça um bom planejamento, tende a diminuir a existência de créditos suplementares. Nesse contexto, existe a possibilidade do município de Cruscilândia ter seu orçamento planejado, obtendo o índice de precisão orçamentária próximo a 0 . Por outro lado, sabe-se que municípios com poucos habitantes possuem um número de transferências per capita maior do que outros com mais habitantes, além da demanda social ser reduzida em relação às grandes cidades. Esses fatores podem influenciar no resultado apresentado.

Com base nas estatísticas descritivas das variáveis que compõem o índice IPOM, foi possível categorizar os municípios mineiros em alto, regular e baixo, de acordo com o nível de precisão orçamentária (ver Quadro 4).

Quadro 4: Nível de precisão orçamentária dos municípios mineiros

\begin{tabular}{|c|l|l|l|}
\hline $\begin{array}{c}\text { Nível de Precisão } \\
\text { Orçamentária }\end{array}$ & \multicolumn{4}{|c|}{ Descrição } & \multicolumn{2}{c|}{ Escore } \\
\hline Alto & $\begin{array}{l}\text { Municípios que apresentaram índice de precisão } \\
\text { orçamentária inferior a um desvio padrão em relação à } \\
\text { média do IPOM. }\end{array}$ & $\mathrm{E}<15,70$ \\
\hline Regular & $\begin{array}{l}\text { Municípios que apresentaram índice de precisão } \\
\text { orçamentária em torno da média do IPOM, estando em um } \\
\text { intervalo de um desvio padrão para menos e um desvio } \\
\text { padrão para mais em relação à média. }\end{array}$ & \multirow{2}{*}{$15,70 \leq \mathrm{E} \leq 35,30$} \\
\hline Baixo & $\begin{array}{l}\text { Municípios que apresentaram índice de precisão } \\
\text { orçamentária superior a um desvio padrão em relação à } \\
\text { média do IPOM. }\end{array}$ & $\mathrm{E}>35,30$ \\
\hline
\end{tabular}

Fonte: dados da pesquisa.

Os dados analisados demonstram que $12,25 \%$ do total de 457 municípios analisados possuem um alto nível de precisão orçamentária, com um escore abaixo de 15,70. Os municípios que apresentaram um nível baixo de precisão orçamentária, com um escore acima de 35,30, representam $10,72 \%$ do total. E 77,02\% do total de municípios se encontram com um escore entre 15,70 e 35,30, perfazendo um nível regular de precisão orçamentária. A quantidade de municípios em cada nível pode ser observada na Tabela 3. 
O escore foi definido através da curva de normalidade gerada pelos dados obtidos do índice IPOM, onde o intervalo de 15,70 a 35,30 vai de um desvio padrão $(9,80)$ para menos e um desvio padrão para mais em relação à média $(25,50)$ do índice.

Tabela 3: Quantidade de municípios em relação ao nível de precisão orçamentária

\begin{tabular}{ccc} 
Nível de Precisão Orçamentária & Número de Municípios & $\%$ \\
\hline Alto & 56 & 12,25 \\
\hline Regular & 352 & 77,02 \\
\hline Baixo & 49 & 10,72 \\
\hline TOTAL & 457 & 100,00 \\
\hline
\end{tabular}

Fonte: dados da pesquisa.

Com intuito de facilitar a visualização da disposição geográfica dos municípios mineiros que apresentaram um nível de precisão orçamentária alto, regular e baixo no período de 2012, foi elaborado o mapa ilustrado na Figura 1.

Figura 1: Representação geográfica dos municípios mineiros em relação ao seu nível de precisão orçamentária.

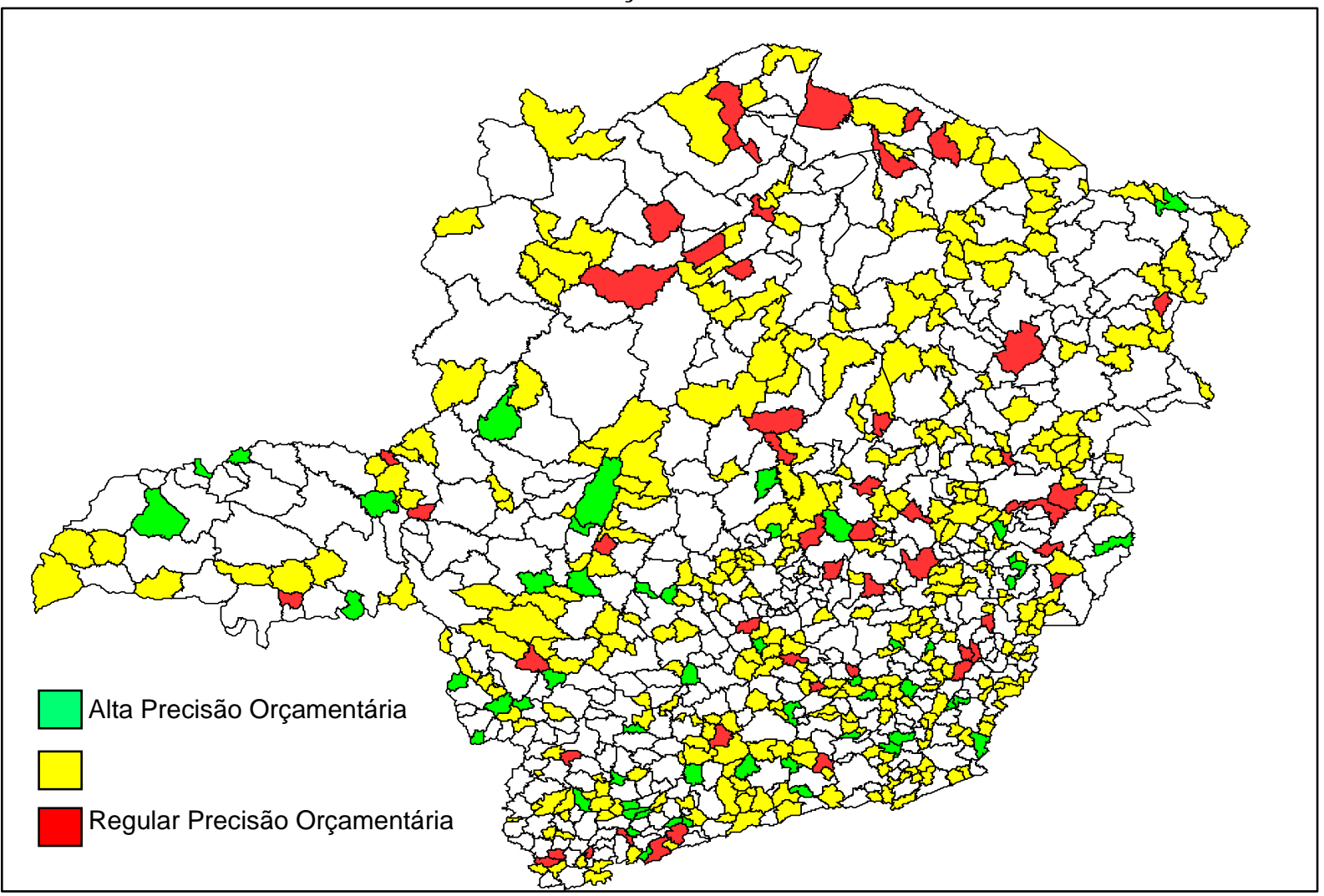

Fonte: dados da pesquisa. 
Pode-se observar que, dos 457 municípios analisados, nos municípios com nível regular de precisão orçamentária, representados pela cor amarela, deu-se de forma homogênea em todo o estado, espalhando-se por todo o território mineiro. Entretanto, os municípios que apresentaram nível de precisão orçamentária alto, representados pela cor verde, localizaram-se nas regiões Centro-Sul e Triângulo Mineiro, com exceção do município de Bandeira que se encontrou no nordeste do estado, enquanto que os municípios que apresentaram nível baixo de precisão orçamentária, representados pela cor vermelha, localizaram-se nas regiões Centro-Norte do estado mineiro.

Percebe-se que a concentração de municípios com baixo nível de precisão orçamentária se encontrará nas regiões Centro-Norte do estado; isso se deve, possivelmente, ao fato de essa região ter um nível econômico mais baixo que as demais regiões do estado, influenciando assim na qualidade da gestão municipal. Por outro lado, as regiões Centro-Sul e Triângulo Mineiro obtiveram uma maior concentração de municípios com alto índice de precisão orçamentária, o que demonstra que, possivelmente, nessas regiões existe uma melhor qualidade da gestão municipal, influenciada pelo maior nível econômico dessas regiões.

\section{CONSIDERAÇÕES FINAIS}

Para que o município tenha um bom planejamento orçamentário, é necessário que este seja o mais preciso possível em sua previsão e execução. Nesse contexto, o presente estudo analisou índices que são importantes para um bom planejamento orçamentário (receitas e despesas), visando atingir o objetivo de mensurar a eficiência dos municípios em relação ao planejamento com o uso dos créditos suplementares.

Para a obtenção dos índices desejados, foram criadas 4 fórmulas, as quais foram aplicadas em 457 municípios mineiros. Essas fórmulas geraram índices que possibilitaram a classificação dos municípios em relação ao nível de precisão orçamentária.

Os resultados demonstraram que, no estado de Minas Gerais, os municípios considerados de pequeno porte (com menos de 10.188 habitantes) obtiveram uma baixa precisão orçamentária no que se refere à receita e à despesa, uma vez que apresentaram indicadores da margem de erro de previsão e execução considerados altos, elevando, assim, a suplementação orçamentária desses municípios.

Outra reflexão que pode ser feita é que, apesar de apresentar indicadores baixos em relação à previsão e à execução de receitas e despesas - sugerindo, num primeiro momento, alta precisão orçamentária -, o município pode apresentar uma alta suplementação orçamentária como 
consequência por não saber distribuir adequadamente suas receitas e suas despesas ao longo das diversas dotações orçamentárias (ou seja, ao longo dos centros de custo), uma vez que a suplementação é fruto de sua má alocação.

Esse alto índice de suplementação pode ser verificado no indicador da média da variável “crédito suplementar", a qual demonstra que a grande maioria dos municípios suplementa seu orçamento em mais de $30 \%$, extrapolando os limites legais.

Acredita-se que o melhor planejamento do orçamento municipal, integrado a um maior conhecimento por parte da gestão, venha diminuir os níveis de suplementação orçamentária desses municípios.

Por fim, verificou-se que, em relação aos níveis de precisão orçamentária, a grande maioria dos municípios se encontra em nível regular. Além disso, existe uma diferença regional entre os municípios que apresentaram índices de precisão orçamentária altos e baixos: aqueles que obtiveram índices baixos representaram o centro-norte do estado, enquanto os que foram classificados com índice alto representaram o centro-sul do estado e o triângulo mineiro, mostrando que há uma probabilidade de que as regiões consideradas economicamente instáveis tenham uma gestão menos efetiva.

Sobre a limitação da pesquisa, destaca-se a disponibilidade dos dados nos sites do FINBRA e TCE-MG apenas para até o ano de 2012, o que não chega a enviesar a pesquisa, mas impossibilita uma análise mais recente. Outro limitador reside na impossibilidade de caracterizar e analisar os motivos que levaram as prefeituras a acionarem a suplementação de crédito - o artigo limitou-se a quantificá-los. Para estudos futuros recomenda-se a aplicação da metodologia em outros municípios, nos estados da federação, no Distrito Federal, e mesmo em escala nacional.

Para estudos futuros, sugere-se que se faça estudos mais profundos nos municípios com destaque positivo e negativo na precisão orçamentária, considerando quais fatores influenciam nos resultados.

\section{REFERÊNCIAS}

ALBUQUERQUE, Edson Dias de. Orçamentos públicos municipais e a abertura de créditos suplementares. Rev. e-Gaia Conhecimento, ano1, n. 1, v. 1, mar. 2014. 
ALESSI, Gil. Entenda o que é a PEC 241 (ou 55) e como ela pode afetar sua vida. EL PAÍS. Disponível em:<http://brasil.elpais.com/brasil/2016/10/10/politica/1476125574_221053.html>. Acesso em: 15 dez. 2016.

ANDRADE, Nilton de Aquino. Contabilidade pública na gestão municipal: métodos com base nas Normas Brasileiras de Contabilidade Aplicadas ao Setor Público (NBCASP) e nos padrões internacionais de contabilidade. 5. ed. São Paulo: Atlas, 2013.

ANGÉLICO, João. Contabilidade pública. 8. ed. São Paulo: Atlas, 2009.

BEZERRA FILHO, João Eudes. Contabilidade pública: teoria, técnica de elaboração de balanços e 500 questões. 2. ed. Rio de Janeiro: Campus, 2006.

BRASIL. Lei n. 4320, de 17 de março de 1964. Estatui normas gerais de direito financeiro para elaboração e controle dos orçamentos e balanços da União, dos Estados, dos Municípios e do Distrito Federal. Diário Oficial da República Federativa do Brasil. Brasília, DF, 1964.

BRASIL. Lei n. 1.079, de 10 de abril de 1950. Define os crimes de responsabilidade e regula o respectivo processo de julgamento. Diário Oficial da República Federativa do Brasil. Brasília, DF, 1950.

BRASIL. Constituição da República Federativa do Brasil de 1988. Emendas Constitucionais. Diário Oficial da República Federativa do Brasil. Brasília, DF, 1988.

BRASIL. Lei n. 101, de 04 de maio de 2000. Estabelece normas de finanças públicas voltadas para a responsabilidade na gestão fiscal e dá outras providências. Diário Oficial da República Federativa do Brasil. Brasília, DF, 2000.

CERVO, Francismary da Ponte. O orçamento público como instrumento de planejamento e controle: análise da execução orçamentária do Instituto Chico Mendes de Conservação da Biodiversidade (período 2008 a 2011). Escola de Administração Fazendária - ESAF. Brasília, 2012.

COSTA, Luiz Marcelo da. Orçamento público: o instrumento da gestão. Porto Alegre: UFRS, 2010.

DARDANHAN, Guilherme. Minas terá alívio de $\mathbf{R} \$ 3$ bilhões com renegociação de dívida. Disponível em: <http://www.defatoonline.com.br/noticias/ultimas/21-06-2016/minas-tera-aliviode-r-3-bilhoes-com-renegociacao-de-divida>. 2016. Acesso em:29 jun. 2016.

GERHARDT, Tatiana Engel; SILVEIRA, Denise Tolfo. Métodos de pesquisa. 1.ed. Porto Alegre: UFRGS, 2009.

HADDAD, Rosaura Conceição; MOTA, Francisco Glauber Lima. Contabilidade pública. Florianópolis, 2010.

KAUARK, Fabiana da Silva; MANHÃES, Fernanda Castro; MEDEIROS, Carlos Henrique. Metodologia da pesquisa: um guia prático. Bahia: Via Litterarum, 2010.

KOHAMA, Heilio. Contabilidade pública: teoria e prática. 9. ed. São Paulo: Atlas, 2003.

Nucleus, v.18, n.1, abr. 2021 
KOHAMA, Heilio. Contabilidade pública: teoria e prática. 12. ed. São Paulo: Atlas, 2012.

MACHADO JR., Teixeira; REIS, Heraldo da Costa. A Lei no 4.320 comentada. 29. ed. Rio de Janeiro: IBAM, 2002.

MORO, Silvio Raul. A interação e a importância do orçamento e dos créditos adicionais na administração pública. Escola de Administração, Porto Alegre, 2011.

ROCHA, Diones Gomes da; MARCELINO, Gileno Fernandes; SANTANA, Cláudio Moreira. Orçamento público no Brasil: a utilização do crédito extraordinário como mecanismo de adequação orçamentária Brasileira. Revista de Administração, São Paulo, v.48, n.4, p.813-827, out./nov./dez. 2013.

ROCHA, C. M. C. Orçamento público no Brasil: um estudo dos créditos adicionais. UnB Contábil, Brasília-DF, v. 4, n. 2, 2001.

RONCALLI, Ângelo. Manuais de gestão pública municipal: contábil e tributário. Associação Mineira de Municípios. v. 6. São Paulo: Ed. Abril, 2009. 79 p.

SANTOS, Aristeu Jorge dos. Orçamento público e os municípios: alguns conceitos e orçamento e suas repercussões na administração pública municipal. Escola de Administração da UFRGS, 2001.

XEREZ, Sebastião Regis Dias. A evolução do orçamento público e seus instrumentos de planejamento. Revista Científica Semana Acadêmica, v. 01, p. 01-10, 2013. 